\title{
Tradition (re)visited: from place to presence $^{1}$
}

\author{
Chiel VAN DEN AKKER*
}

\begin{abstract}
Three ways of encountering objects belonging to our cultural heritage can be distinguished. We may encounter an object in its traditional environment, we may encounter an object in an environment of preservation, and we may encounter an object in an environment of representation. These three ways of encountering objects provide a framework for addressing the question of how we relate to cultural heritage by means of digital media. Digital reproductions of our cultural heritage belong to the third way of encountering objects. In our present day, we first and foremost relate to tradition by representing it, whereas before we first and foremost related to tradition by remembering it. Places of memory are exchanged for the presence of representation in a culture driven by information technology.
\end{abstract}

Key words: Digitization, authenticity, tradition, memory, representation, historical consciousness.

Digital imaging, simulations, reconstructions, search engines and visualization are but a few examples of representing tradition with the help of information technology. ${ }^{2}$ These technologies not only change the practices of cultural heritage institutions entrusted with the task of preserving tradition; they also change the way we relate ourselves to tradition.

Three ways of encountering objects belonging to our cultural heritage will be distinguished by using the concepts of authenticity, consciousness, memory and history. This way we will acquire a conceptual framework that enables us to address the question of how we relate to cultural heritage by means of digital media. This framework will also help us to surpass the binary oppositions in terms of which this question is usually dealt with - opposition such as the real versus the virtual, the material versus the immaterial, and the original versus the copy. ${ }^{3}$

I will argue that in our present day we first and foremost relate to tradition by representing it, whereas in former times we first and foremost maintained a relation to tradition by remembering it. Places of memory are exchanged for the presence of representation in a culture driven by information technology. 


\section{TRADITION VISITED}

There are three ways we may encounter an object belonging to our cultural heritage. An object can be part of tradition, it can remind us of once being part of tradition, and the object being part of tradition can be represented or itself be representative of that tradition. I take objects to be tangible heritage as well as the intangible heritage associated with it.

Coming across an object in its original environment means encountering that object in the environment of its original use value. Think, for example, of a farmer ploughing his field, a Catholic visiting his church, a cave painting depicting a successful hunt, or an imperial statue causing a feeling of awe and submissiveness. Here the plough, the church, the painting, the statue and their associated practices are part of the domain of tradition.

A second way we may encounter an object is in an environment preserving that object, while visiting an archaeological excavation or a museum, for example. The farmer's tools may be exhibited in a museum. The church may at some moment cease to function as a place of worship and instead be turned into a monument to be visited during opening hours. The cave painting may lose its ability to provide a successful hunt and turn out to be pre-historic art. The imperial statue, apart from being removed to protect it from weather and greenhouse gases, may no longer give rise to a feeling of awe and submissiveness in its visitor, and instead be admired for its aesthetic qualities, even if the statue reminds its visitor of its original use value. Objects in an environment of preservation are reminiscent of the tradition that the objects once belonged to.

A third way we may encounter an object is in its documented or representational environment. Reading information concerning the provenance of an object or a story about farmers and Catholics is such a means of encountering objects. Words are not the only way to document an object. A photograph, if not an artwork in its own right, is a means of documenting an object, too. Similarly, a reconstruction of a peasant village documents that village. Visiting a reconstruction of a prehistoric cave or a Roman forum is visiting a place documenting that cave or forum.

The domain of representation also encompasses objects that are representative of their own past. These objects are documents themselves. If a plough is exhibited in a series of farmer's tools representing agricultural tradition, the plough may lose its autonomy and become a document in itself, representative of the tradition it once belonged to. If a museum exhibits an object in a reconstruction or mimetic recreation of a traditional environment, then the object is displayed in situ. If an object is exhibited in such a way that the object is representative of the tradition it once belonged to, then the object is displayed in context. ${ }^{4}$ In both these cases, the objects represent tradition.

Digital objects are representations and therefore belong to the third way of encountering objects. The digital reproduction of cultural heritage consists mostly of digital imaging. Far from purporting to be surrogates of original objects, these digital images represent relevant features of the objects they reproduce. ${ }^{5}$ Of course, even if they were surrogates and would be hovering above our terminals as holograms, they would still be reproductions and therefore representations of original objects. Many cultural heritage institutions also provide online search engines to search their database. These databases are 
documentations (representations) of collections. Museums may also try to get users involved in this documentation process by tempting them to tag objects. Virtual reconstructions, simulations, 3D modelling and Geographic Information Systems (GIS) are also representations of the objects and their original environment, whether accessible online or as part of a museum exhibition. All these activities document tradition by representing it. The virtual museum may for that reason be called a documentation museum.

For a proper understanding of these three ways of encountering objects belonging to our cultural heritage, we must realize that the same object at one moment is part of the first domain, at another part of the second domain, and at some moment will only be encountered by means of its representation or as representative of its tradition. The encounter determines what the object is like.

We should also keep in mind that museum practices have a history, too: they are part of a tradition of collecting and exhibiting. This not only explains why there are such things as museums of museums - that is, museums documenting museum practices - but also why an object is preserved or turned into a document.

Not all objects once belonged to tradition. This is true of such things as natural stones and seashells, except of course those stones and shells that were collected for their magical, aesthetic or representative qualities. Stones in a museum of natural history, for example, are collected for being representative of some part of the past and thus were once part of a tradition of collecting natural history objects.

\section{TRADITION, AUTHENTICITY AND THE VIRTUAL}

The concept of authenticity may help us better understand these three ways of encountering objects. The authenticity of a thing is according to Walter Benjamin "the essence of all that is transmissible from its beginning, ranging from its substantive duration to its testimony to the history which it has experienced." ${ }^{6}$ Authenticity is thus something that an object acquires. To be authentic, an object needs to accumulate a history, establishing in retrospect the authenticity of that object.

Following this definition of authenticity, we may contend that in an environment of preservation objects are preserved for having collected a history. ${ }^{7}$ The concept of authenticity in an environment of preservation thus refers to the object's former environment: the domain of tradition in which the object collected its history. We may say something similar regarding the concept of authority: the authority of an object in an environment of preservation depends on its original use value. For the reference to its original use value provides the object with an aura of authority.

The authenticity of an object in the sense of its accumulated history is not the only sense of authenticity we have. For one can also argue that the authenticity of objects depends on its documentation. In that case, the authenticity of an object in a preserved environment refers to its documentation. Again, the same is true of the concept of authority. It is because experts make and control the records of objects that their documentation is authoritative. Documenting is not just a matter of the administration, registration and preservation of information. Documenting objects is in the first place providing historical testimonies, and with it a sense of authenticity and authority.

There are thus two senses of authenticity. Authenticity in the sense of the object's accumulated history and authenticity in the 
sense of its documentation. Only unique objects can accumulate such history, for only unique objects have a singular existence in time. Reproductions, on the other hand, are at best part of the history of the unique item. They do not collect a history by themselves, for they have no singular existence in time, as Benjamin emphasized. ${ }^{8}$ So reproductions can only be related to the second sense of authenticity. A reproduction documents the object it is a reproduction of.

Once could oppose distinguishing between these two senses of authenticity by arguing that there is but one sense since the second sense is simply a record of the first. Moreover, the documentation of the object gives us the accumulated history rather than the other way around. The authenticity of an object is a social construct, depending on dominant curatorial and discursive practices, leaving no room for authenticity in its first sense. ${ }^{9}$ This argument need not convince us. For in case of the second sense of authenticity, it is indifferent whether the object is materially present or not, while the reverse does not hold. Since there is a difference between the presence and absence of material objects, there is a difference between authenticity as the accumulated history of the object and authenticity as the documentation or testimony of the object. This difference is obviously important when discussing the difference between objects and their digital reproductions.

Museums and archaeological sites guard the authenticity of objects by preserving them. In a digital environment, we encounter virtual and immaterial reproductions of those artefacts instead. Since these reproductions lack a singular existence in time, they have not accumulated a history and therefore lack authenticity. It follows that virtual museums cannot function as guardians of the 109 authenticity of objects. Next, one could argue that in a virtual environment the distinction between reproduction and heritage disappears. Since a digital file is identical to its copy, there is no difference to be made between copies and originals in a virtual environment. The reproduction of our heritage, then, implies losing the connection with heritage itself. This is even more so if we realize that in a virtual environment objects are everywhere at any time as long as they are processed.

Both arguments are much rehearsed in studies on the impact of new media, making use of respectively the original-copy and the material-immaterial opposition. But there is more to it. If heritage is encountered apart from any sense of place and time, we may doubt whether there is still anything left of our sense of cultural heritage. Along these lines, Jeff Malpas has warned us that "that which is culturally significant is not mere 'information' but is itself tied to particular places and things". This "sense of place" is "bound up intimately with a sense of heritage, as well as with a sense of culture. Thus, inasmuch as new media threatens our sense of place, so it also threatens our sense of cultural heritage". ${ }^{10}$ The same might be argued in terms of time. If new media threaten our sense of time, they also threaten our sense of cultural heritage. So digital reproductions of our cultural heritage threaten our sense of authenticity (and closely related notions such as "authority"), for the authenticity of an object is its collected history, and that history is in danger of getting lost in a virtual environment.

But, as we have argued, authenticity in the sense of the object's accumulated history is not the only sense of authenticity we have. The authenticity of an object can also be identified 
110 with its documentation. So even if the first sense of authenticity is lost in a virtual environment, the second sense might still be there, taking the place of the first. If so, the virtual museum might be called a documentation museum.

Moreover, all representation - not just the digital ones - must be linked to this second sense of authenticity. All reconstructions, all representative objects, are representations and in that sense virtual, immaterial and nonunique, too. So if we argue that the virtual museum is a documentation museum representing our cultural heritage, we do not return to using binary oppositions to formulate the difference that digital media makes. For a digital object in a virtual museum and a material object encountered in an environment of documentation are no different in that they both represent our cultural heritage. ${ }^{11}$ A painting exhibited in such a way that it is only representative of the tradition it once belonged to, is as such virtual and immaterial, too. If an object is representative, the distinction between that object and its documentation evaporates, for the object is itself a document. Digital objects are just one of the ways we encounter objects in our present-day culture.

In a digital environment in which collections are documents, the distinction between an object and its documentation can also no longer be maintained. Of course, there is still a distinction to be made between the digital image of some object and its written documentation. But the distinction between the digital image itself and the written documentation is no longer a distinction between an object and its documentation. This is not so much because the boundaries between texts and images are blurring in digital environments (images are no longer primarily illustrative of accompanying texts and texts are no longer primarily comments on accompanying images), but simply because both the digital image and the written accounts are data files documenting cultural heritage.

One could further argue that in a virtual environment there is a need for documentation. Since digital files are so easily multiplied and distributed, they need to be anchored to the object they document. If not, representations will eventually only be identified as belonging to a certain type instead of also being about a particular object. Rigaud's painting of Louis XIV may then first turn into a Louis XIVpainting and subsequently into a king-painting or even a man-with-wig-painting. Furthermore, by anchoring the digital file to the object, the file is linked to the place where the original object is kept. That way the documentation can still be verified.

Digital reproductions of our cultural heritage belong to the third way of encountering objects only. They document tradition by representing it. Before I further argue this, I will first elaborate on the three ways of encountering objects.

\section{TRADITION, MEMORY, AND HISTORY}

The environment of an object's original use value is the domain of tradition. This is the domain of habits, gestures and skills passed down from generation to generation. ${ }^{12}$ These habits, gestures and skills might be called embodied memories: they are stored in the body as practices. Memory may also be characterized as imitative. Habits, gestures and skills must be learned, and by repeating them tradition is transmitted. Moreover, practices constitute the tradition by carrying tradition on from one generation to the other. Finally, 
memory may be called natural memory. In the domain of tradition, memory is unmediated, direct and something that is not being reflected upon. If a farmer uses a tool, he may have learned to use that tool from his ancestors, but that is not something he reflects upon while using that tool. A Catholic visiting his church on Sunday will worship his God; he will not reflect on his God being worshipped in a certain way.

In the domain of tradition, there is no difference to be made between tradition on the one hand and being conscious of that tradition on the other, for they are one. Habits, gestures and skills, when used, are consciously performed actions embodying tradition, but they are not the object of conscious reflection at the same time. In being part of tradition, the object accumulates its history unnoticed. The moment one starts reflecting on tradition and thus becomes conscious of tradition as such is the moment tradition is on the verge of getting lost, only to be remembered or represented. This brings me to the second domain.

The environment of preservation is the domain of what remains from the past, the domain of materiality. Here the environment becomes a site of memory, a lieux de mémoire, as Pierre Nora has called it. ${ }^{13}$ This is the moment in which the farmer's plough is no longer used for ploughing, the moment God is no longer worshipped, the cave painting stops assisting hunts, and the statue loses its imperial power, even though they will all still be there to be visited. Of essential importance is that memory here refers to what has been lost. The objects we encounter on a site of memory, once part of tradition, now remind us of that tradition. Archaeological excavations and museums are such sites of memory. However, a national holiday, a melody, a landscape may also function as a site of memory. ${ }^{14} \mathrm{On}$ a site of memory, we seek "the decipherment of what we are in the light of what we are no longer", according to Nora. ${ }^{15}$ How we may become what we are no longer is not explained by Nora. I propose the following explanation, based on the methods of dialectics.

To explain how we become what we are no longer, we must realize that in the realm of preservation tradition and being consciousness of tradition diverge. A plough may remind us of a lost agricultural tradition, a church of a lost tradition of devotion, a cave painting of a lost world of magic, and an imperial statue may remind us of a lost world of divine earthly rule. On a site of memory, tradition is not handed over, but one becomes aware of the break with tradition, of a past being over. ${ }^{16}$ The object is then no longer connected to its original environment and use value. Instead, the connection between the object and its origin and history has become a reflective one. ${ }^{17}$

This separation of tradition and consciousness is a first phase. The second phase starts the moment in which what is unfamiliar becomes familiar. Then what is no longer turns into what we are no longer through a process of identification. This moment of becoming what one is no longer is a moment of becoming selfconscious. Now we can say that the object reminds us of what we are no longer.

The opposition between tradition and being conscious of the tradition is at the same time preserved and overcome in making the tradition part of a former self. What was at first distant and unfamiliar has become part of ourselves. We see ourselves in terms of what we are no longer: that is what the object reminds us of. What is no longer has become a memory of our former selves, transcending the 
112 boundaries of our personal history into the remote past.

In the domain of preservation, the object becomes a means for reflection on what has been and thus triggers what is known as historical consciousness. The object's accumulated history, unnoticed in the realm of tradition, has now surfaced. Tradition and being conscious of tradition have separated, the former having become the object of the latter.

Tradition, memory and history are closely related notions. ${ }^{18}$ The moment traditions are historicized is the moment historiography can come into being. Here our heritage may have a critical function and stimulate us to reflect on our present day by questioning it. It does so if it reminds us of what we are no longer. We not only need to be critical towards the past, the past must be equally critical towards the present as well.

Not only material objects and its related practices may remind us of what we are no longer. An important addition to this must be made. Historical narratives may show us what tradition was like. As such they would be part of the domain of representation. But historical narratives may also express a sense of what we are no longer. Inasmuch as we are able to identify ourselves with what is being expressed, the work may transform the immediate environment of the reader into a site a memory, thus functioning as a site of memory itself.

The third domain is the domain of representation, of photographs, of description, of metadata and of information on the provenance of objects. This is the domain of documentation. Here our heritage is (re)constructed. Instead of memory being imitative, as in the domain of tradition, memory is mimetic and preserved by being stored. Tradition no longer needs to be remembered since it is already represented. Memory in the domain of representation is best described as mediated memory.

Being conscious of tradition now is mediated by representation. Consciousness and tradition, although seemingly opposed since the representation stands for the represented, are actually one, for the representation defines what the represented tradition was like. This is why the domain of representation is also the domain of invented traditions, of representations that suggest representing traditions that in fact never existed. ${ }^{19}$ To be sure, not all represented traditions are invented traditions.

In this domain, heritage has no critical function, although the representation itself can be the result of a critical attitude towards the heritage it represents. For tradition or cultural heritage to have a critical function, it must remind us of what we are no longer. And that cannot be achieved by representing heritage as if we were part of it. That only shows us what it would have been like. An object reminding us of what we are no longer does not function on the level of representation, but on the level of memory. Being an image, a photograph shows us what the past was like, whereas its materiality may remind us of what we are no longer. ${ }^{20}$

The domain of representation is also the domain of reproduction and reconstruction. Some museums are sites of documentation rather than sites of memory. This is the case when their collection consists of reproductions instead of original objects, for reproductions have never been part of the domain of tradition. A reproduction is a representation of a thing belonging to tradition. ${ }^{21}$ Museums are also sites of documentation when they reconstruct or simulate the domain of 
tradition. Then the exhibition of objects purports to show the past as contemporaries then saw it, thus aiming at (an illusion of) immediacy. ${ }^{22}$ A reconstruction of a peasant village documents that village, just as the reconstructed cave of Lascaux documents the original cave and its paintings, turning the reconstruction into a document itself. So-called experience rooms, historic theme parks, reenactments and historical films all fall under this rubric of reconstructions of tradition.

Preserving objects easily turns into documenting them. This happens when the object becomes valued for its representative qualities instead of its particularity. If an artwork is considered to be representative of some period style, then the artwork will document or represent that period style. So an artwork may express a lost tradition of worship, but once the painting is representative of late medieval art, the painting loses its expressive power. It follows that museums should be careful when exhibiting their artworks in an art historical context, that is, as long as they want their artworks to work and embody their historicity. When we start seeing museums as centres of information rather than as repositories of particular objects, ${ }^{23}$ we deprive museums of their role as sites of memory and allocate them the function of documentation centres only.

\section{TRADITION REVISITED}

In our present day, we first and foremost relate to tradition by representing it, while before that we first and foremost related to tradition by remembering it. Digital imaging, simulations, search engines, 3D modelling and so forth are the outcome of a process in which documentation is taking the place of sites of memories, just as from the nineteenth century onwards sites of memory started taking the place of natural memory. Nora prophesized along these lines that: "A generalized critical history would no doubt preserve some museums, some medallions and monuments (...) but it would empty them of what, to us, would make them lieux de mémoire. In the end, a society living wholly under the sign of history could not, any more than could a traditional society, conceive such sites for anchoring its memory." ${ }^{24}$ History, virtual or not, in the sense of a representation or documentation of tradition (and thus not expressing what one is no longer) causes sites of memory to disappear. In the age of documentation, we relate to tradition by means of its representation. Cultural heritage, then, is its documentation. Remembering tradition is exchanged for representing it. This shift does not limit itself to virtual environments only, but applies to physical museums as well. If curators no longer experience the objects before compiling an exhibition and only consult their database, that is, their documentation, it is clear that a shift from sites of memories to sites of documentation has taken place inside the museum itself. Evidently is the use of digital media inside museums exemplary of this shift, too.

Above we distinguished between two senses of authenticity. The virtual museum is first and foremost a documentation museum, representing unique objects by documenting them. As a consequence, authenticity in the sense of documentation is becoming dominant in our time, taking the place of authenticity in the sense of the object's collected history.

That in the age of documentation we no longer relate to tradition other than by means of its representation, would not be the entire 
114 story, however. Two recent developments must be mentioned here. First, museums also use the web to collect information such as stories about the local environment of its users. These stories not only document the local environment, but may also transform that local environment into a site of memory. If you come to know that your favourite park was a palatine in the past, you may experience visiting that park differently. This may explain the popularity of local environment projects. A second development to be mentioned here is the technology known as augmented reality. Think, for example, of the possibility of walking down the street and watching on your iPhone pictures of that street from centuries ago. The pictures themselves document the environment, but while walking down the street they may also transform the environment into a site of memory, ${ }^{25}$ reminding us of what we are no longer, thereby questioning our present day so we do not take it for granted. If so, authenticity in the sense of the object's collected history, its historicity, might still be part of our sense of cultural heritage.

Transforming environments into sites of memory is not limited to local environment projects and augmented reality applications. All representation can make us see the world we live in differently. The point is that when tradition is represented, there is usually no need to be reminded of the tradition our former selves were once part of.

So there is this possibility that as some point we only relate to tradition by representing it. That would be the moment in which places of memory are exchanged for the presence of representations. I am not sure if or when that moment arrives. Time will not tell, for only places can.

\section{NOTER}

1. The research for this essay was funded by NWO (the Netherlands Organization for Scientific Research).

2. Examples and analysis of these impressive technologies can be found in Mark Greengrass and Lorna Hughes eds. (2008) and Manos Baltsavias, Armin Gruen, Luc van Goold, and Maria Pateraki eds. (2006).

3. For a critical analysis of these oppositions and their shortcomings, see Fiona Cameron (2007).

4. On the distinction between displaying in situ and displaying in context, see Kirshenblatt-Gimblett (1998, pp. 19-23).

5. David Arnold (2008, p. 159).

6. Benjamin (1999, p. 215).

7. An object taken out of its original environment does not cease to collect a history in the sense that in a preserved environment, the history of the object becomes part of the history of collecting and exhibiting practices of the institution preserving that object.

8. Benjamin (1999, p. 214)

9. On authenticity as a social construct, see Cameron (2007, pp. 54-57). In Cameron's analysis there is no room for our first sense of authenticity. Cf. below $n 11$.

10. Malpas (2008, p. 198).

11. Cameron argues against the non-materiality of digital objects and concludes (p. 70): "Both modalities, the analog and the digital, are material objects by definition, each acting as testimony to its own history and origin, and hence authenticity and aura". This we can agree with inasmuch as objects are representative of some part of the past and authenticity is taken in its second sense of documentation.

12. This characterization is Pierre Nora's (1989, p. 13).

13. According to Nora (1989, p. 12): "Lieux de mé- 
moire originate with the sense that there is no spontaneous memory, that we must deliberately create archives, maintain anniversaries, organize celebrations, pronounce eulogies, and notarize bills because such activities no longer occur naturally."

14. Monuments and memorials are sites of memory, too, reminding us of what once was and is no longer. A ritual of commemoration, on the other hand, is, as a ritual, part of tradition. Most monuments and memorials have lost their ability to remind us of what is no longer and have become what below will be called documents of the past.

15. Nora (1989, p. 18). On the awareness of what we are no longer, see also Frank Ankersmit's analysis of Hegel on the conflict between Socrates and the Athenian State (2005, pp. 330-334).

16. Since its inception, it was complained that museums destroy "the life of art and history by preserving it”. See Didier Maleuvre (1999, pp. 1-2).

17. This is of course a Hegelian theme. Maleuvre summarizes as follows (1999, p. 27): "to Hegel, the mediation of historical consciousness has the opposite effect of the alienation commonly imputed to it: plucking the artwork out of its natural context does not sever it from its context but presents this context as what it in fact always is, a product of mind. Hegel would say that the relation of the Elgin marbles to antiquity (...) is more reflective once this connection is actually taken out of its immediate circumstance (...). The relation of the statue to its cultural origin stands out more clearly as a reflective connection, rather than a natural one."

18. After discussion several explanations for the rise of memory in historical discourse from the end of the nineteen eighties onwards, Kerwin Klee Klein (2000, p. 145) concludes that we want memory to "re-enchant our relation with the world and pour presence back into the past". Our relationship with tradition by means of its historio- graphic representation is according to Klein (and others) in crises. Here Klein comes close to Nora (1989, pp. 10-11), although not being aware of that. Nora also points at the crises in historiography, that is, "the reflexive turning of history upon itself" and its failure to relate to tradition. On the diverse relationships that history and memory are presumed to have, see Geoffrey Cubitt (2007, pp. 26-65).

19. On invented traditions, see Eric Hobsbawm and Terence Ranger eds. (1983).

20. Materiality and being an image might not be that easily separated. But there is a difference between triggering a memory of what has been and representing what it has been like. Since objects easily turn into representations (see below), the function of representation will presumably take the upper hand in most cases. On the distinction between the photograph's materiality and the photograph being an image and the ambivalence the distinction gives rise to, see Michael Roth (2009).

21. A plough is a mass-produced object and in that sense a reproduction. But a plough is not a representation of a plough once belonging to tradition. A plough can be representative of tradition and represent it.

22. Allan Megill (2007, p. 214) warns us about this sort of aesthesis (sensation) of history in our present day culture. In line with what we have said, Megill argues that it withholds us from experiencing a break between "what we are now and what other were then".

23. In 1992, the then director of the Canadian Museum of Civilization George MacDonald argued that museums should be seen as information centres. See Cameron (2007, pp. 51-52).

24. Nora (1989, p. 9).

25. In the description of augmented reality by Nadia Magnenat-Thalmann and George Papagiannakis (2006, pp. 419-430), the augmented reality ap- 
116 plication turns into a simulation and thus not transforms the environment into a site of memory.

\section{REFERENCES}

Ankersmit, F. Sublime Historical Experience (Stanford 2005).

Arnold, D. "Digital Artefacts: Possibilities and Purpose" in: Greengrass, M. and L. Hughes eds. The Virtual Representation of the Past (Farnhem 2008) pp. 159-170.

Baltsavias, M., A. Gruen, L. Goold, and M. Pateraki eds. Recording, Modeling and Visualization of Cultural Heritage (London 2006).

Benjamin, W. "The work of Art in the Age of Mechanical Reproduction" in: Illuminations ed. H. Arendt (London 1999) pp. 211-244.

Cameron, F. "Beyond the Cult of the Replicant Museums and Historical Digital Objects: Traditional Concerns, New Discourses" in: F. Cameron and S. Kenderdine eds. Theorizing Digital Cultural Heritage. A Critical Discourse (Cambridge and London 2007) pp. 49-75.

Cubitt, G. History and Memory (Manchester 2007).

Greengrass, M. and L. Hughes eds. The Virtual Representation of the Past (Farnhem 2008).

Hobsbawm, E. and T. Ranger eds. The Invention of Tradition (Cambridge 1983).

Kirschenblatt-Gimblett, B. Destination Culture. Tourism, Museums, and Heritage (Berkeley, Los Angeles, London 1998).

Klein, K. "On the Emergence of Memory in Historical Discourse" in: Representations 69 (2000) pp. 127-150.

Magnenat-Thalmann, N. and G. Papagiannakis. "Virtual Worlds and Augmented Reality in Cultural Heritage Applications" in: Baltsavias, M., A. Gruen, L. Goold, and M. Pateraki eds. Recording, Modeling and Visualization of Cultural Heritage (London 2006) pp. 419-430.
Maleuvre, D. Museum Memories. History, Technology, Art (Stanford 1999).

Malpas. "New Media, Cultural Heritage and the Sense of Place: Mapping the Conceptual Ground" in: International Journal of Heritage Studies 14 (2008) pp. 197-209.

Megill, A. Historical Knowledge, Historical Error. A contemporary guide to practice (Chicago and London 2007).

Nora. "Between Memory and History: Les Lieux de Mémoire" in: Representations 26 (1989) pp. 7-24.

Roth, M. "Photographic Ambivalence and Historical Consciousness" in: History and Theory (2009) pp. 82-94.

${ }^{*}$ Dr. Chiel van den Akker, PhD in Philosophy in 2009. Since then he is lecturer and researcher Historical Theory at the history department of the VU University Amsterdam. As a postdoctoral researcher he is involved in the CATCHAgora project (http:/lagora.cs.vu.nl). His research focuses on the interpretation and representation of objects in cultural heritage institutions by means of information and communication technology.

Address: Faculty of Arts, Department of History, VU University Amsterdam Boelelaan 1105, 1081 HV Amsterdam

Email: c.vanden.akker@let.vu.nl 